\title{
FAKTOR PENYEBAB KETERLAMBATAN PENYEDIAAN REKAM MEDIS RAWAT JALAN DI RUMAH SAKIT KURNIA CILEGON
}

\author{
Aliyah Az Zahra, Leni Herfiyanti \\ Politeknik Piksi Ganesha, Indonesia ${ }^{1,2}$ \\ aliyah.icha9@gmail.com ${ }^{1}$; leniherfiyanti@gmail.com ${ }^{2}$
}

Received: 26-06-2021

Revised : 14-07-2021

Accepted: 24-07-2021

\begin{abstract}
Abstrak
Latar belakang: Ketepatan waktu dalam penyediaan rekam medis merupakan suatu hal yang sangat penting untuk menunjang pelayanan yang baik untuk pasien, namun beberapa hal membuat penyediaan rekam medis menjadi terlambat.
\end{abstract}

Tujuan: Penelitian ini bertujuan untuk menganalisis faktorfaktor keterlambatan penyediaan rekam medis rawat jalan di Rumah Sakit Kurnia Cilegon.

Metode: Metode penelitian yang digunakan adalah metode kualitatif untuk menganalisis faktor penyebab keterlambatan dalam penyediaan rekam medis di bagian filing dengan menggunakan unsur $5 \mathrm{M}$ (man, material, methode, machine, money) untuk mengidentifikasi faktor penyebab keterlambatan dalam penyediaan rekam medis di pelayanan rawat jalan. Teknik pengumpulan data menggunakan observasi dan wawancara kepada petugas rekam medis.

Hasil: Dari hasil penelitian didapatkan bahwa faktor penyebab keterlambatan dalam penyediaan rekam medis adalah rekam medis yang hilang, rusak, dan masih dalam peminjaman.

Kesimpulan: Hasil penelitian menunjukkan bahwa pendidikan dan pengetahuan petugas rekam medis masih kurang, tidak diadakan pelatihan, tidak diadakan evaluasi sehingga Standar Operasional Prosedur (SOP) pendistribusian dan peminjaman tidak dijalankan secara maksimal, rak yang tidak dapat menyimpan rekam medis karena terlalu penuh dan map rekam medis yang mudah rusak.

Kata kunci: rekam medis; keterlambatan; penyediaan; rawat jalan.

\footnotetext{
Abstract

Background: Timeliness in providing medical records is a very important thing to support good service for patients, but several things make the provision of medical records late.

Objective: This research aims to analyze and determine the factors of delay in providing outpatient medical records at Kurnia Hospital Cilegon.

Method: The research method used is a qualitative method
} 
to analyze the factors causing delays in providing medical records in the filing section using $5 M$ elements (man, material, method, machine, money) to identify factors causing delays in providing medical record files in outpatient services. Data collection techniques using observation and interviews with medical record officers. Results: From the results of the study, it was found that the factors causing delays in the provision of medical record files were medical record files that were lost, damaged, and were on loan.

Conclusion: The results showed that the education and knowledge of medical record officers was still lacking, no training was held, no evaluation was held so that the officers did not comply with the distribution SOP, loans that were not returned according to the time set by the SOP, small storage space, shelves that could not store record files medical records again because they are too full, the medical record file folder is easily damaged.

Keywords: medical records; lateness; provision; outpatient.

*Correspondence: Aliyah Az-Zahra

Email: aliyah.icha9@gmail.com

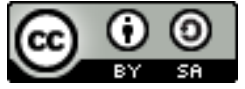

\section{PENDAHULUAN}

Menurut Undang-Undang Republik Indonesia Nomor 44 Tahun 2009 tentang rumah sakit dijelaskan bahwa Rumah Sakit adalah institusi pelayanan kesehatan yang menyelenggarakan pelayanan kesehatan perorangan secara paripurna yang menyediakan pelayanan rawat inap, rawat jalan, dan gawat darurat. Salah satu hal terpenting dalam menunjang pelayanan rumah sakit adalah rekam medis (Indonesia, 44 C.E.). Menurut (Permenkes, 2008) Nomor 269/MENKES/PER/III/2008, Rekam Medis adalah sebuah berkas yang berisikan catatan dan dokumen tentang identitas pasien, hasil pemeriksaan, pengobatan dan pelayanan penunjang lain yang telah diberikan kepada pasien. Setiap rumah sakit harus membuat rekam medis baik pelayanan rawat jalan ataupun rawat inap karena rekam medis adalah alat bukti tertulis atas segala pelayanan, perkembangan penyakit dan pengobatan selama pasien berkunjung atau dirawat di rumah sakit, juga rekam medis mampu melindungi dan digunakan untuk kepentingan hukum apabila dikemudian hari terjadi suatu hal yang tidak diinginkan menyangkut rekam medis itu sendiri.

Rumah Sakit Kurnia Cilegon adalah rumah sakit swasta tipe $\mathrm{C}$ yang merupakan perkembangan dari Rumah Sakit Ibu dan Anak (RSIA) Kurnia Cilegon yang memulai kegiatan operasional pada tahun 1982 dengan nama Rumah Bersalin Kurnia dengan kapasitas sebanyak 4 kamar rawat. Dalam kurun waktu 21 tahun, perkembangan teknologi, ilmu pengetahuan, dan ilmu terapan terus meningkatkan sumber daya manusia. Sehingga, dengan sumber daya manusia yang berilmu dan kompeten dikembangkanlah fasilitas pelayanan obstetric dan ginekologi, serta pelayanan poliklinik umum 24 jam. Maka dari itu, dengan pesatnya perkembangan pelayanan kesehatan di Rumah Sakit Kurnia Kota Cilegon membuat rumah sakit ini dipilih sebagai rumah sakit rujukan Badan Penyelenggaraan Jaminan Sosial (BPJS) di Kota Cilegon. Mutu merupakan keseluruhan karakteristik dan gambaran dari suatu barang dan jasa yang menunjukkan kemampuannya dalam memuaskan kebutuhan pelanggan (Wulandari et al., 2019). Maka dapat dikatakan 
bahwa mutu merupakan sesuatu yang digunakan guna menjamin suatu tujuan dan mutu harus terus ada perkembangan yang terkini agar dapat menjamin kepuasan pasien.

Pelayanan kesehatan di rumah sakit menjadi perhatian utama manajemen rumah sakit karena dengan pelayanan yang baik dan prima pasien pun akan merasa puas dengan pelayanan yang diberikan selama kunjungan atau pengobatan (Az-Zahroh, 2017). Pelayanan kesehatan merupakan setiap upaya yang diselenggarakan sendiri atau secara bersama-sama dalam suatu organisasi untuk memelihara kesehatan, meningkatkan kesehatan, mencegah penyakit, menyembuhkan penyakit serta memulihkan kesehatan baik perseorangan, keluarga, suatu kelompok, ataupun masyarakat (Kemendagri, 2009). Pelayanan yang cepat dan tepat adalah keinginan semua konsumen atau pasien baik pemberi pelayanan maupun menerima pelayanan. Kecepatan dan ketepatan penyediaan rekam medis menjadi salah satu indikator kepuasan pasien (Wati et al., 2020). Semakin cepat rekam medis rawat jalan sampai ke poliklinik maka semakin cepat pelayanan yang diberikan dokter kepada pasien.

Dari pengamatan awal diketahui bahwa Rumah Sakit Kurnia sudah menetapkan Standar Pelayanan Minimal (SPM) "10 menit dalam penyediaan rekam medis rawat jalan sampai rekam medis di poliklinik. Sebagaimana telah diatur dalam Keputusan Menteri Kesehatan RI No.129/MENKES/SK/II/2008 tentang standar pelayanan minimal rumah sakit (Depkes, 2008). Namun dalam penyediaan rekam medis rawat jalannya masih kurang maksimal, sebab masih adanya keterlambatan penyediaan rekam medis rawat jalan serta tidak sesuai dengan waktu yang sudah ditetapkan pada Standar Operasional Prosedur (SOP).

Berdasarkan uraian di atas, penulis tertarik untuk melaksanakan penelitian Di Rumah Sakit Kurnia Cilegon dengan tujuan untuk menganalisis faktor-faktor keterlambatan penyediaan rekam medis rawat jalan di Rumah Sakit Kurnia Cilegon. Keterlambatan penyediaan rekam medis rawat jalan dapat mempengaruhi kualitas pelayanan medis kepada pasien (

\section{METODE PENELITIAN}

Jenis penelitian ini dilakukan dengan menggunakan metode kualitatif dengan pendekatan unsur 5M (man, money, material, methode, machine). Populasi pada penelitian ini yaitu rekam medis rawat jalan pada bulan Mei 2021 sebanyak 2,044 rekam medis. Besar sampel dalam penelitian ini menggunakan rumus Slovin.

$$
\begin{gathered}
n=\frac{N}{1+N e^{2}} \\
n=\frac{2044}{1+2044 * 0,1^{2}} \\
n=\frac{2044}{21,44} \\
n=95,33 \\
n \approx 95
\end{gathered}
$$

Berdasarkan hasil perhitungan sampel yang digunakan sebanyak 95 rekam medis. Subjek dalam penelitian ini adalah 2 petugas rekam medis bagian filing.

Pengumpulan data yang digunakan observasi yaitu faktor dari penyebab keterlambatan penyediaan rekam medis rawat jalan di Rumah Sakit Kurnia Cilegon dan 
wawancara yang dilakukan kepada 2 petugas rekam medis untuk mengetahui tanggapan dari petugas dalam menyediakan rekam medis rawat jalan dan apa yang menjadi faktor penyebab keterlambatan dalam penyediaan rekam medis rawat jalan.

Analisis data yang digunakan adalah teknik analisis kualitatif dengan pendekatan hasil observasi, pengambilan random sampling data pengembalian rekam medis oleh bagian casemix, dan wawancara yang dilakukan pada bulan Mei 2021 serta menghubungkan unsur 5M (man, money, material, methode, machine) untuk mengidentifikasi faktor penyebab keterlambatan dalam penyediaan rekam medis di pelayanan rawat jalan.

\section{HASIL DAN PEMBAHASAN}

\section{A. Hasil Penelitian}

Sistem penomoran di Rumah Sakit Kurnia Cilegon menggunakan sistem unit (unit numbering system). Sistem penyimpanan rekam medis yang digunakan adalah sistem sentralisasi dan sistem penjajarannya secara straight numerical filing system.

Peminjaman rekam medis mempunyai prosedur yang telah diatur dalam Standar Operasional Prosedur (SOP) Rumah Sakit Kurnia, bahwa untuk peminjaman rekam medis dari semua instalasi yang membutuhkan rekam medis. Tujuannya untuk mempermudah pengendalian rekam medis dan tata tertib rekam medis. Adapun prosedur yang diterapkan adalah setiap ruangan yang akan meminjam, datang ke ruang rekam medis untuk mengisi nama dan tanggal peminjam pada buku peminjaman dengan ketentuan rekam medis rawat jalan dan Instalasi Gawat Darurat (IGD) wajib dikembalikan maksimal 1x24 jam dan ketentuan rekam medis rawat inap wajib dikembalikan maksimal $2 \times 24$ jam. Peminjam bertanggung jawab atas kehilang atau kerusakan rekam medis, jika dalam jangka waktu yang telah ditentukan rekam medis belum dikembalikan maka petugas rekam medis akan menghubungi peminjam agar rekam medis segera dikembalikan.

Pendistribusian rekam medis mempunyai prosedur yang telah diatur dalam Standar Operasional Prosedur (SOP) Rumah Sakit Kurnia, bahwa proses pendistribusian rekam medis dari ruang rekam medis ke poliklinik atau ruang perawatan pasien. Tujuannya adalah sebagai pedoman guna meningkatkan mutu pelayanan kesehatan. Adapun prosedur yang diterapkan petugas rekam medis yaitu menerima permintaan rekam medis yang dicetak melalui printer yang terhubung dengan bagian pendaftaran atau melalui telepon. Lalu, setelah permintaan rekam medis diterima maka petugas rekam medis mengambil outguide dan menempelkan hasil cetak permintaan rekam medis pada outguide. Kemudian petugas rekam medis mencari dan mengambil rekam medis di rak sesuai nomor paisen yang akan berobat serta menempelkan outguide pada rak rekam medis yang diambil. Lalu, petugas mendistribusikan rekam medis ke poliklinik yang dituju dengan waktu tunggu pendistribusian rekam medis \pm 10 menit.

Penyimpanan rekam medis telah diatur dalam Standar Operasional Prosedur (SOP) Rumah Sakit Kurnia, bahwa proses penyimpanan rekam medis dilakukan oleh petugas rekam medis dan rekam medis yang telah selesai digunakan baik pelayanan rawat jalan, rawat inap, dan Instalasi Gawat Darurat (IGD) harus dikembalikan ke ruang rekam medis. Untuk cara penyimpanannya, rekam medis dikelompokkan berdasarkan nomor rekam medis yang tertera pada rekam medis pasien. Nomor tersebut dapat dilihat dari angka sebelah kiri, tengah, dan kanan. Lalu, rekam medis dapat disimpan kembali pada rak penyimpanan. 
Identifikasi Ketidaktersediaan Rekam medis Rawat Jalan di Rumah Sakit Kurnia Cilegon

Berdasarkan observasi yang dilakukan pada bulan Mei 2021, peneliti mengumpulkan data. Data yang telah didapat akan disajikan dengan tabel berikut:

Tabel 1. Hasil observasi keterlambatan penyediaan rekam medis pada bulan Mei 2021

\begin{tabular}{cccc}
\hline No. Nomor Rekam Medis $\quad$ Waktu (menit) & $\begin{array}{l}\text { Missfile } \\
\text { (Rekam } \\
\text { Medis) }\end{array}$ & $\begin{array}{c}\text { Rusak } \\
\text { (Rekam } \\
\text { Medis) }\end{array}$ \\
\hline
\end{tabular}

\begin{tabular}{|c|c|c|c|c|}
\hline 1 & 110127 & 16 & $\checkmark$ & - \\
\hline 2 & 156387 & 15 & $\checkmark$ & - \\
\hline 3 & 093467 & 11 & - & $\checkmark$ \\
\hline 4 & 056843 & 14 & $\checkmark$ & - \\
\hline 5 & 216696 & 17 & $\checkmark$ & - \\
\hline 6 & 206072 & 11 & - & $\checkmark$ \\
\hline 7 & 051231 & 15 & $\checkmark$ & - \\
\hline 8 & 237437 & 12 & - & $\checkmark$ \\
\hline 9 & 153072 & 12 & $\checkmark$ & - \\
\hline 10 & 054376 & 9 & - & $\checkmark$ \\
\hline 11 & 015083 & 13 & $\checkmark$ & - \\
\hline 12 & 209901 & 12 & - & $\checkmark$ \\
\hline 13 & 114357 & 10 & - & $\checkmark$ \\
\hline 14 & 198558 & 15 & $\checkmark$ & - \\
\hline 15 & 014133 & 13 & $\checkmark$ & - \\
\hline 16 & 125023 & 12 & - & $\checkmark$ \\
\hline 17 & 226554 & 9 & - & $\checkmark$ \\
\hline 18 & 220617 & 17 & $\checkmark$ & - \\
\hline 19 & 123424 & 12 & - & $\checkmark$ \\
\hline 20 & 044552 & 16 & $\checkmark$ & - \\
\hline 21 & 140488 & 16 & $\checkmark$ & - \\
\hline 22 & 200553 & 9 & - & $\checkmark$ \\
\hline 23 & 045402 & 18 & $\checkmark$ & - \\
\hline 24 & 099544 & 15 & $\checkmark$ & - \\
\hline 25 & 116911 & 17 & $\checkmark$ & - \\
\hline 26 & 220990 & 13 & - & $\checkmark$ \\
\hline 27 & 150241 & 14 & - & $\checkmark$ \\
\hline 28 & 175022 & 16 & $\checkmark$ & - \\
\hline 29 & 226732 & 10 & - & $\checkmark$ \\
\hline 30 & 117124 & 18 & $\checkmark$ & - \\
\hline 31 & 105584 & 14 & - & $\checkmark$ \\
\hline 32 & 017610 & 14 & $\checkmark$ & - \\
\hline 33 & 015720 & 17 & $\checkmark$ & - \\
\hline
\end{tabular}




\begin{tabular}{|c|c|c|c|c|}
\hline 34 & 215216 & 10 & - & $\checkmark$ \\
\hline 35 & 133032 & 18 & $\checkmark$ & - \\
\hline 36 & 116126 & 18 & $\checkmark$ & - \\
\hline 37 & 136357 & 12 & - & $\checkmark$ \\
\hline 38 & 117908 & 10 & - & $\checkmark$ \\
\hline 39 & 171107 & 13 & $\checkmark$ & - \\
\hline 40 & 172431 & 9 & - & $\checkmark$ \\
\hline 41 & 084801 & 15 & $\checkmark$ & - \\
\hline 42 & 206260 & 13 & - & $\checkmark$ \\
\hline 43 & 181320 & 10 & $\checkmark$ & - \\
\hline 44 & 222337 & 15 & $\checkmark$ & - \\
\hline 45 & 124249 & 12 & $\checkmark$ & - \\
\hline 46 & 227188 & 14 & $\checkmark$ & - \\
\hline 47 & 204587 & 12 & - & $\checkmark$ \\
\hline 48 & 225017 & 12 & $\checkmark$ & - \\
\hline 49 & 185299 & 10 & - & $\checkmark$ \\
\hline 50 & 225273 & 12 & $\checkmark$ & - \\
\hline 51 & 153162 & 10 & - & $\checkmark$ \\
\hline 52 & 171002 & 14 & $\checkmark$ & - \\
\hline 53 & 215187 & 11 & $\checkmark$ & - \\
\hline 54 & 142106 & 10 & - & $\checkmark$ \\
\hline 55 & 236184 & 14 & $\checkmark$ & - \\
\hline 56 & 113691 & 15 & $\checkmark$ & - \\
\hline 57 & 128431 & 14 & - & $\checkmark$ \\
\hline 58 & 216811 & 16 & $\checkmark$ & - \\
\hline 59 & 163499 & 11 & $\checkmark$ & - \\
\hline 60 & 086224 & 13 & $\checkmark$ & - \\
\hline 61 & 057800 & 10 & - & $\checkmark$ \\
\hline 62 & 115634 & 12 & - & $\checkmark$ \\
\hline 63 & 230390 & 17 & $\checkmark$ & - \\
\hline 64 & 145180 & 9 & - & $\checkmark$ \\
\hline 65 & 235884 & 14 & $\checkmark$ & - \\
\hline 66 & 236365 & 10 & $\checkmark$ & - \\
\hline 67 & 127065 & 12 & - & $\checkmark$ \\
\hline 68 & 168905 & 15 & $\checkmark$ & - \\
\hline 69 & 216824 & 10 & - & $\checkmark$ \\
\hline 70 & 136991 & 12 & $\checkmark$ & - \\
\hline 71 & 237730 & 11 & - & $\checkmark$ \\
\hline 72 & 216710 & 14 & $\checkmark$ & - \\
\hline 73 & 130421 & 10 & $\checkmark$ & - \\
\hline 74 & 227201 & 9 & - & $\checkmark$ \\
\hline
\end{tabular}




\begin{tabular}{|c|c|c|c|c|}
\hline 75 & 236359 & 14 & $\checkmark$ & - \\
\hline 76 & 228734 & 14 & $\checkmark$ & - \\
\hline 77 & 153465 & 12 & $\checkmark$ & - \\
\hline 78 & 236686 & 9 & - & $\checkmark$ \\
\hline 79 & 236442 & 13 & $\checkmark$ & - \\
\hline 80 & 237499 & 10 & - & $\checkmark$ \\
\hline 81 & 237190 & 12 & - & $\checkmark$ \\
\hline 82 & 217100 & 15 & $\checkmark$ & - \\
\hline 83 & 172856 & 11 & - & $\checkmark$ \\
\hline 84 & 076682 & 14 & $\checkmark$ & - \\
\hline 85 & 196874 & 13 & - & $\checkmark$ \\
\hline 86 & 236943 & 10 & - & $\checkmark$ \\
\hline 87 & 145540 & 13 & $\checkmark$ & - \\
\hline 88 & 100183 & 9 & - & $\checkmark$ \\
\hline 89 & 202315 & 14 & $\checkmark$ & - \\
\hline 90 & 237333 & 15 & $\checkmark$ & - \\
\hline 91 & 235932 & 10 & - & $\checkmark$ \\
\hline 92 & 091119 & 15 & $\checkmark$ & - \\
\hline 93 & 165660 & 14 & $\checkmark$ & - \\
\hline 94 & 057349 & 12 & - & $\checkmark$ \\
\hline 95 & 228885 & 10 & - & $\checkmark$ \\
\hline Total & 95 & 1209 & 54 & 41 \\
\hline
\end{tabular}

Sumber: Data yang diobservasi, 2021

Rata-rata waktu penyediaan 95 rekam medis memerlukan waktu 12,72 menit. Berdasarkan tabel 1, dapat disimpulkan bahwa:

Tabel 2. Ketersediaan Penyediaan Rekam Medis

\begin{tabular}{|c|c|c|c|c|c|c|}
\hline No. & Keterangan & $\begin{array}{c}\text { Total } \\
\text { Waktu }\end{array}$ & $\begin{array}{c}\text { Total } \\
\text { Rekam } \\
\text { Medis }\end{array}$ & $\begin{array}{l}\text { Rata- } \\
\text { Rata } \\
\text { Waktu }\end{array}$ & $\begin{array}{c}\text { Presentase } \\
(\%)\end{array}$ & Kesimpulan \\
\hline 1. & Missfile & 772 & 54 & 14,29 & $26,46 \%$ & $\begin{array}{lr}\text { Rekam medis } & \text { missfile } \\
\text { disebabkan kelalaian } & \text { saat } \\
\text { petugas rekam } & \text { renyimpanan rekan } \\
\text { medis ke rak, } 54 \text { rekam } \\
\text { medis missfile } \\
\text { memerlukan rata-rata } \\
\text { waktu penyediaan } \\
14,28 \text { menit }(26,46 \%) \\
\text { dimulai dari pencarian, } \\
\text { rekam medis ditemukan } \\
\text { sampai berada di } \\
\text { poliklinik dengan } \\
\text { waktu terlama adalah } \\
18 \text { menit }\end{array}$ \\
\hline
\end{tabular}




\begin{tabular}{|c|c|c|c|c|c|c|}
\hline & & 437 & & & & $\begin{array}{l}\text { Rekam medis yang } \\
\text { terlipat, } \\
\text { mengakibatkan rusak, } \\
41 \text { rekam medis rusak } \\
\text { memerlukan rata-rata } \\
\text { waktu penyediaan }\end{array}$ \\
\hline 2. & Rusak & 431 & 41 & 10,65 & $25,91 \%$ & $\begin{array}{l}10,05 \text { menit }(25,9 \%) \\
\text { dimulai dari pencarian, } \\
\text { perbaikan rekam medis, } \\
\text { sampai berada di } \\
\text { poliklinik dengan } \\
\text { waktu terlama adalah } \\
14 \text { menit. }\end{array}$ \\
\hline
\end{tabular}

Sumber: Data yang diolah penulis, 2021

Menurut (Mirfat et al., 2017) bahwa adanya keterlambatan pengembalian rekam medis ke bagian assembling dapat mengganggu pelayanan. Khususnya keterlambatan pengembalian rekam medis oleh bagian casemix ke bagian assembling sangat berpengaruh untuk pasien post rawat inap Badan Penyelenggaraan Jaminan Sosial (BPJS) datang ke rumah sakit untuk kontrol. Ketika pasien mendaftar, petugas mencari rekam medisnya namun tidak ditemukan dan petugas harus menghubungi bagian casemix untuk mengetahui keberadaan rekam medis. Selanjutnya, jika rekam medis tersebut dikonfirmasi berada di ruangan casemix, petugas casemix akan mencari dan menghantarkan rekam medis yang dibutuhkan ke ruang rekam medis. Hal tersebut sangat mempengaruhi pelayanan karena membutuhkan waktu untuk mencari dan menghantarkan.

Berdasarkan pengambilan random sampling yang dilakukan pada bulan Mei 2021 peneliti mengumpulkan 10 data rekam medis dipinjam oleh bagian casemix untuk proses klaim Badan Penyelenggaraan Jaminan Sosial (BPJS) dan didapatkan data yang akan disajikan dengan tabel berikut:

Tabel 2. Hasil Observasi Keterlambatan Pengembalian Rekam Medis Akibat Dipinjam oleh Casemix pada Bulan Mei 2021

\begin{tabular}{ccccccc}
\hline No. & No RM & $\begin{array}{c}\text { Tanggal } \\
\text { Masuk }\end{array}$ & $\begin{array}{c}\text { Tanggal } \\
\text { Keluar }\end{array}$ & $\begin{array}{c}\text { Tanggal } \\
\text { Kembali }\end{array}$ & Jaminan & $\begin{array}{c}\text { Keterlam } \\
\text { batan }\end{array}$ \\
\hline 1. & 234887 & $01 / 05 / 2021$ & $10 / 05 / 2021$ & $17 / 05 / 2021$ & $\begin{array}{c}\text { BPJS } \\
\text { Mandiri }\end{array}$ & 5 hari \\
\hline 2. & 174704 & $01 / 05 / 2021$ & $09 / 04 / 2021$ & $13 / 05 / 2021$ & $\begin{array}{c}\text { BPJS } \\
\text { PNS/Peru } \\
\text { sahaan }\end{array}$ & 2 hari \\
\hline 3. & 225742 & $07 / 05 / 2021$ & $12 / 05 / 2021$ & $16 / 05 / 2021$ & $\begin{array}{c}\text { BPJS } \\
\text { PNS/Peru } \\
\text { sahaan }\end{array}$ & 2 hari \\
\hline 4. & 234910 & $10 / 05 / 2021$ & $14 / 05 / 2021$ & $19 / 05 / 2021$ & $\begin{array}{c}\text { BPJS } \\
\text { Mandiri }\end{array}$ & 3 hari \\
\hline 5 & 188731 & $13 / 05 / 2021$ & $16 / 05 / 2021$ & $24 / 05 / 2021$ & $\begin{array}{c}\text { BNSS } \\
\text { PNS/Peru } \\
\text { sahaan }\end{array}$ & 6 hari \\
\hline 6. & 144731 & $13 / 05 / 2021$ & $20 / 05 / 2021$ & $26 / 05 / 2021$ & $\begin{array}{c}\text { BPJS } \\
\text { PNS/Peru } \\
\text { sahaan }\end{array}$ & 4 hari \\
\hline 7. & 234486 & $16 / 05 / 2021$ & $22 / 05 / 2021$ & $25 / 05 / 2021$ & BPJS & 1 hari \\
\hline
\end{tabular}




\begin{tabular}{ccccccc}
\hline & & & & \multicolumn{3}{c}{ Mandiri } \\
\hline 8. & 232312 & $17 / 05 / 2021$ & $19 / 05 / 2021$ & $28 / 05 / 2021$ & $\begin{array}{c}\text { BPJS } \\
\text { PNS/Peru } \\
\text { sahaan }\end{array}$ & 7 hari \\
\hline 9. & 192039 & $18 / 05 / 2021$ & $24 / 05 / 2021$ & $31 / 05 / 2021$ & $\begin{array}{c}\text { BPJS } \\
\text { Mandiri }\end{array}$ & 5 hari \\
\hline 10. & 158754 & $19 / 05 / 2021$ & $24 / 05 / 2021$ & $27 / 05 / 2021$ & $\begin{array}{c}\text { BPJS } \\
\text { Mandiri }\end{array}$ & 1 hari \\
\hline
\end{tabular}

Sumber: Data yang diobservasi, 2021

Berdasarkan tabel 2, hasil observasi keterlambatan pengembalian rekam medis akibat dipinjam oleh casemix pada bulan mei 2021, keterlambatan pengembalian rekam medis paling lama adalah 7 hari. Untuk mengidentifikasi ketidaktersediaan rekam medis rawat jalan, peneliti juga melakukan wawancara kepada 2 petugas rekam medis, berikut hasil wawancara:

Tabel 3. Wawancara Petugas Rekam Medis

\begin{tabular}{ccl} 
No. Subjek Penelitian & \multicolumn{1}{c}{ Keterangan } \\
\hline & & \multicolumn{1}{c}{ "Yang menjadi penyebab keterlambatan penyediaan } \\
& rekam medis karena kurangnya fokus saat penyimpanan \\
1 & rekam medis ke rak, ketika butuh rekam medis tersebut \\
& kita harus mencari terlebih dahulu dan biasanya itu \\
& memakan waktu cukup lama" \\
& & "Saat ada permintaan rekam medis dan saya \\
& & mencarinya seringkali rekam medisnya tidak dapat \\
& & ditemukan (missfile), dipinjam oleh casemix tetapi \\
& belum kembali, atau salah susun saat penyimpanan"
\end{tabular}

Sumber: Petugas Rekam Medis, 2021

Berdasarkan tabel 3, hasil wawancara tersebut dapat disimpukan bahwa adanya kesalahan penyimpanan rekam medis yang terjadi saat penyusunan rekam medis rawat jalan yang kembali dari poliklinik menuju rak penyimpanan karena ketidaktelitian (human error). Sehingga, saat ada permintaan rekam medis dan petugas pencari rekam medis yang dibutuhkan atau diminta tidak dapat ditemukan (missfile). Kemudian petugas casemix meminjam rekam medis untuk proses pengklaiman Badan Penyelenggara Jaminan Sosial (BPJS) sesuai dengan Standar Operasional Prosedur (SOP) peminjaman rekam medis yang telah ditetapkan bahwa rekam medis pelayanan rawat jalan dan Instalasi Gawat Darurat (IGD) wajib dikembalikan maksimal 1x24jam sedangkan rekam medis rawat inap wajib dikembalikan maksimal $2 \times 24$ jam. Namun, didapatkan beberapa kali saat adanya permintaan rekam medis rawat jalan dari bagian pendaftaran atau poliklinik rekam medis yang dibutuhkan berada di ruangan casemix karena belum kembalinya berkas tersebut ke ruang rekam medis atau dikarenakan belum selesai dikerjakan oleh bagian casemix. Maka dari hal tersebut, dapat disimpulkan bahwa belum sesuai dengan Standar Operasional Prosedur (SOP) yang berlaku.

\section{B. Pembahasan}

Menganalisis Faktor Penyebab Keterlambatan dalam Penyediaan Rekam Medis
Rawat Jalan di Rumah Sakit Kurnia Cilegon

1. Faktor Man 
Man, yang dimaksud dalam penelitian ini merujuk kepada petugas rekam medis menjadi aspek utama dalam sirkulasi rumah sakit. Petugas rekam medis mempunyai tugas dan tanggung jawab yang besar dalam menjaga keutuhan sebuah rekam medis dan diharapkan dapat benar-benar mengetahui sejarah dari rekam medis secara luas dan mendalam guna menunjang kinerja yang dilakukan baik, telaten, dan memuaskan. Di Rumah Sakit Kurnia Cilegon terdapat 11 petugas rekam medis dengan rincian sebagai berikut :

Tabel 4. Kualifikasi Karyawan Rekam Medis

\begin{tabular}{clccc}
\hline No. & \multicolumn{1}{c}{ Jabatan } & Kualifikasi & Frekuansi & Presentase (\%) \\
\hline 1. & Kepala Rekam Medis & D3 Rekam Medis & 1 & $9,09 \%$ \\
\hline 2. & Petugas Assembling & SMA & 1 & $9,09 \%$ \\
\hline 3. & $\begin{array}{l}\text { Petugas Filing dan } \\
\text { Pendistribusian }\end{array}$ & SMA & 8 & $72,73 \%$ \\
\hline 4. & Petugas Pelaporan HIV & SMA & 1 & $9,09 \%$ \\
\hline
\end{tabular}

Sumber: Data Karyawan, 2021

Berdasarkan tabel 4, hanya 1 dari 11 petugas rekam medis yang memiliki kualifikasi D3 Rekam Medis adapun petugas lainnya memiliki kualifikasi pendidikan SMA. Yang mana dari hasil observasi ini menyatakan bahwa petugas rekam medis yang bekerja belum sesuai standar yang telah ditetapkan berdasarkan Peraturan Menteri Kesehatan Nomor 55 Tahun 2013 tentang Penyelenggaraan Pekerjaan Perekam Medis bahwa perekam medis dan informasi kesehatan adalah seseorang yang telah lulus pendidikan Rekam Medis \& Informasi Kesehatan (RMIK) sesuai ketentuan peraturan perundang-undangan (Menkes, 2013).

Menurut analisis penulis, petugas dengan pendidikan yang lebih tinggi ditunjang pengalaman dan pelatihan akan memiliki pengetahuan, kedisiplinan, kualitas kerja yang lebih baik dibanding petugas baru. Hal ini sejalan dengan penelitian (Wijayanti \& Nuraini, 2017) bahwa pendidikan tinggi berpengaruh besar terhadap pengetahuan dan informasi yang dapat terlihat pada keterampilan serta keberhasilan tugasnya.

2. Faktor Money

Money atau uang merupakan salah satu unsur yang penting dan tidak bisa diabaikan, uang merupakan alat tukar juga sebagai alat pengukur nilai. Oleh karena itu uang merupakan alat yang penting untuk mencapai tujuan dan segala sesuatu yang harus diperhitungkan secara rasional. Untuk mencapai pelayanan yang baik dan cepat sesuai dengan yang diharapkan oleh pasien anggaran merupakan faktor penting yang menentukan rumah sakit. Berikut hasil wawancara terkait pengadaan anggaran dana dalam penyediaan berkas rekam medis rawat jalan di Rumah Sakit Kurnia Cilegon:

Tabel 5. Ketersediaan Anggaran Dana Penyediaan Rekam Medis di Rumah Sakit Cilegon

\begin{tabular}{ccc}
\hline No. & Subjek Penelitian & \multicolumn{1}{c}{ Keterangan } \\
\hline 1. & Petugas 1 & $\begin{array}{l}\text { "Anggaran sih pasti ada, karena ada pihak } \\
\text { yang mengurus tentang anggaran tersebut" }\end{array}$ \\
\hline 2. & Petugas 2 & $\begin{array}{l}\text { "Kalau tentang anggaran dana saya kurang } \\
\text { tau, tapi pastinya sih ada" }\end{array}$ \\
\hline
\end{tabular}

Berdasarkan hasil wawancara, anggaran dana dalam penyediaan rekam medis sebenarnya ada namun anggaran yang ada belum mencukupi kebutuhan rekam medis. Proses penganggaran di rumah sakit merupakan salah satu proses manajemen 
keuangan yang sangat penting sebagai alat perencanaan dan pengendalian kegiatan operasional rumah sakit. Menurut (Setyawan \& Supriyanto, 2020) bahwa anggaran dikoordinasi pada semua bagian yang ada di rumah sakit sehingga saling menunjang serta saling bekerja sama untuk menuju hasil yang ditentukan. Jika sudah terencana dan terkendali kegiatan operasional rumah sakit pun dalam mencapai efisiensi dan efektifitas dalam pengelolaannya.

\section{Faktor Material}

Material atau bahan baku adalah suatu yang merujuk pada bahan baku utama untuk diolah sampai menjadi produk akhir untuk diserahkan kepada konsumen. Dalam faktor ini yang menjadi bahan baku adalah rekam medis. Berdasarkan hasil observasi, pada saat adanya permintaan rekam medis masih didapatkan rekam medis dengan kondisi yang rusak, terlipat, robek, tercecer dari map bahkan hilang (missfile), karena untuk rekam medis rawat jalan tidak semuanya menggunakan map masih didapatkan rekam medis yang tidak menggunakan map sehingga itu yang menjadi penyebab tercecernya rekam medis. (Pujilestari et al., 2016) bahwa rekam medis yang tidak menggunakan tracer menyebabkan berkas tersebut missfile atau salah letak. Banyaknya rekam medis yang menumpuk di rak filing yang tidak menggunakan map juga menjadi salah satu faktor penyebab keterlambatan dalam penyediaan rekam medis. Rekam medis yang dipinjam oleh bagian casemix guna pengklaiman Badan Penyelenggaraan Jaminan Sosial (BPJS) juga menjadi salah satu faktor keterlambatan karena perlu meminta ke bagian casemix terlebih dahulu untuk mengambil rekam medis yang dibutuhkan. Sehingga, dari kondisi rekam medis yang belum semuanya dalam keadaan baik, peminjaman rekam medis oleh bagian casemix dapat memakan waktu yang lama dalam proses pencarian dan penyediaan rekam medis.

4. Faktor Methode

Methode atau metode berasal dari bahasa Yunani methodos yang berarti cara atau kerja yang ditempuh. Methode dalam Rumah Sakit merupakan cara, sistem atau prosedur kerja yang dilakukan dalam penyediaan rekam medis rawat jalan yang tentunya ditetapkan oleh Standar Operasional Prosedur (SOP) yang berperan sebagai acuan bagi para petugas dalam meningkatkan kinerja dan sumber daya yang ada sehingga kinerja yang dilakukan bisa berjalan dengan baik dan efisien dan dalam proses penyediaan rekam medis rawat jalan bisa menjadi lebih patuh terhadap Standar Operasional Prosedur (SOP) yaitu <10 menit. (Hakam, 2018) bahwa pemahaman petugas terhadap SOP masih kurang karena tidak ada sosialisasi secara menyeluruh dan tidak adanya controlling dalam monitoring kesesuaian SOP. Adapun untuk sistem penyimpanan rekam medis, Rumah Sakit Kurnia Cilegon menggunakan sistem penyimpanan sentralisasi dan menggunakan sistem penjajaran straight numeric filling (angka langsung).

Berdasarkan hasil observasi, tidak adanya evaluasi yang dilakukan terkait Standar Operasional Prosedur (SOP) yang berlaku menyebabkan adanya petugas kebingungan dengan alurnya. Menurut (Stiyawan et al., 2018) bahwa evaluasi terhadap SOP itu perlu dilakukan agar pelaksanaan SOP akan terbuka terhadap penyempurnaan agar bisa memperoleh prosedur yang benar-benar efektif dan efisien. Dapat disimpulkan bahwa yang menjadi penyebab keterlambatan penyediaan rekam medis karena tidak adanya evaluasi terkait Standar Operasional Prosedur (SOP) yang berlaku yang mana adanya evaluasi sangat diperlukan agar petugas paham dalam menjalankan tugasnya dengan baik dan juga tersedianya rekam medis yang tepat waktu.

5. Faktor Machine

Machine atau mesin adalah alat yang berguna untuk mengubah gaya menjadi energi, dimana energi tersebut dapat dimanfaatkan oleh manusia di berbagai kegiatan, penggunaannya dipercaya dapat mempermudah segala aktivitas yang ada. Suatu mesin atau alat yang dapat mempemudah petugas filing dalam menyediakan rekam medis 
adalah rak penyimpanan rekam medis atau roll o'pac. Menurut (Ritonga \& Ritonga, 2018) bahwa adanya perencanaan dan penambahan rak penyimpanan rekam medis berdasarkan standar ergonomi yaitu rak penyimpanan yang berupa rak rak roll o'pack. Berikut hasil wawancara terkait ketersediaan rak penyimpanan rekam medis:

Tabel 5. Ketersediaan Rak Penyimpanan Rekam Medis

\begin{tabular}{lll}
\hline No. & Subjek Penelitian & Keterangan \\
\hline 1. & Petugas 1 & $\begin{array}{l}\text { "Rak penyimpanan tidak memadahi, perlu } \\
\text { banget ada penambahan rak" }\end{array}$ \\
\hline 2. & Petugas 2 & $\begin{array}{l}\text { "Belum ada penambahan rak, masih banyak } \\
\text { rekam medis aktif yang tidak masuk rak dan } \\
\text { akhirnya disimpan dalam kardus" }\end{array}$ \\
& &
\end{tabular}

Sumber: Hasil Wawancara, 2021

Berdasarkan hasil wawancara, didapatkan jumlah rak penyediaan rekam medis yang tersedia belum memadahi. Rekam medis aktif yang masih digunakan banyak yang disimpan didalam kardus. Hal ini menimbulkan tercecernya rekam medis.

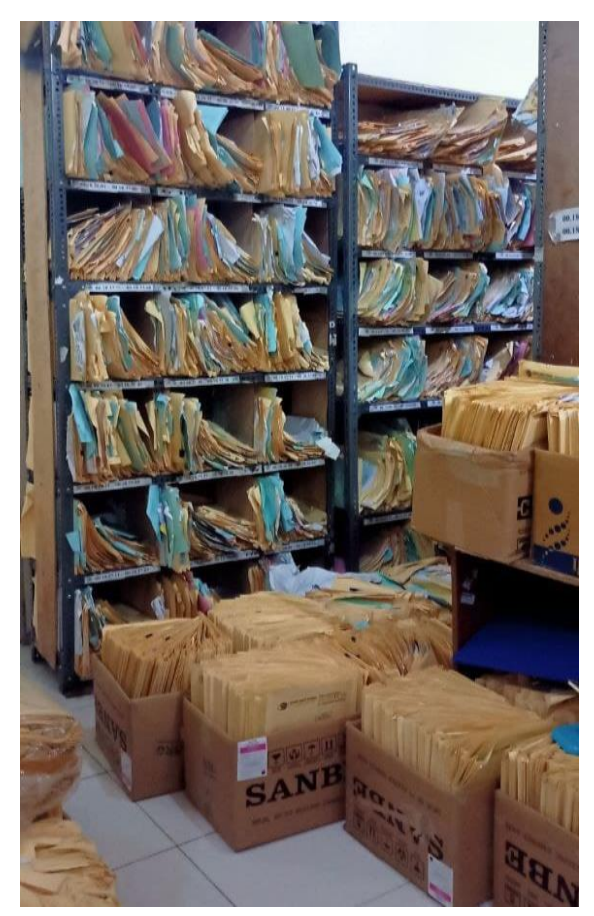

Gambar 1. Rak Penyimpanan Rekam Medis Rumah Sakit Kurnia Cilegon

Gambar 1 menunjukkan kondisi rak penyimpanan rekam medis di Rumah Sakit Kurnia Cilegon, dimana ruang penyimpanannya tidak memadahi. Sehingga, kardus dijadikan tempat untuk penyimpanan rekam medis dengan nomor baru.

\section{KESIMPULAN}

Berdasarkan analisis data beserta interpretasinya, dapat disimpulkan ketidaktersediaan rekam medis paling besar terjadi karena missfile $26,46 \%$ dan keterlambatan pengembalian rekam medis paling lama 7 hari yang disebabkan karena 
petugas casemix yang meminjam rekam medis tidak mengembalikan rekam medis tepat waktu.

Berdasarkan faktor penyebab keterlambatan penyediaan rekam medis dengan unsur 5M (man, money, material, methode, machine), dapat disimpulkan sebagai berikut: Faktor Man, tingkat pendidikan petugas rekam medis yang masih dengan kualifikasi Sekolah Menengah Atas (SMA), kedisiplinan petugas dalam mengatur waktu, pengalaman bekerja di rekam medis, masih belum diberikan pelatihan rutin guna menambah wawasan petugas dan meningkatkan kinerja petugas. Faktor Money, penyediaan anggaran dana belum mencukupi kebutuhan rekam medis. Faktor Material, kondisi rekam medis yang kondisi yang rusak, terlipat, robek, tercecer dari map bahkan hilang dan rekam medis yang dipinjam oleh bagian casemix. Faktor Methode, kesalahan meletakkan dalam penyimpanan rekam medis ke dalam rak, rekam medis yang berada di lantai yang tidak tersusun kedalam rak penyimpanan. Faktor Machine, masih menggunakan rak biasa belum roll o'pac, rak yang tersedia tidak dapat memadahi penyimpanan rekam medis yang aktif.

\section{BIBLIOGRAFI}

Az-Zahroh, T. N. (2017). Pengaruh Mutu Pelayanan Kesehatan Terhadap Tingkat Kepuasan Pasien Rawat Inap di Ruang Dewasa Umum Rumah Sakit X Kabupaten Gresik. PSIKOSAINS (Jurnal Penelitian Dan Pemikiran Psikologi), 12(2), 99-111.

Depkes, R. I. (2008). Keputusan Menteri Kesehatan RI No. 829/Menkes. SK/IV/2008 tentang Standar Pelayanan Minimal di Rumah Sakit. www. depkes. go. id.

Hakam, F. (2018). Analisis Penyediaan Rekam Medis Pasien Rawat Jalan Berdasarkan Standar Operasional Prosedur (SOP) Di Puskesmas X. Jurnal Manajemen Informasi Dan Administrasi Kesehatan (JMIAK), l(1).

INDONESIA, P. R. (44 C.E.). Undang-Undang Republik Indonesia Nomor 44 Tahun 2009 Tentang Rumah Sakit.

Kemendagri, R. I. (2009). Undang-Undang Republik Indonesia Nomor 44 Tahun 2009 tentang Rumah Sakit. Jakarta: Departemen Kesehatan RI.

Menkes, R. I. (2013). Peraturan Menteri Kesehatan RI Nomor 55 Tahun 2013 tentang Penyelenggaraan Pekerjaan Rekam Medis. Jakarta: Indonesia.

Mirfat, S., Andadari, N., \& Indah, Y. N. N. (2017). Faktor Penyebab Keterlambatan Pengembalian Dokumen Rekam Medis di RS X Kabupaten Kediri. JMMR (Jurnal Medicoeticolegal Dan Manajemen Rumah Sakit), 6(2), 174-186.

Permenkes, R. I. (2008). No 269/Menkes/Per/III/2008 tentang Rekam Medis. Jakarta: Menteri Kesehatan Reupublik Indonesia.

Pujilestari, A., Arief Kurniawan, N. P., \& SKM, M. (2016). Pelaksanaan Penyimpanan Berkas Rekam Medis Berdasarkan Unsur Manajemen 5 m Di RskiaPermata Bunda Yogyakarta. Universitas Muhammadiyah Surakarta.

Ritonga, Z. A., \& Ritonga, N. A. (2018). Analisa Kebutuhan Rak Penyimpanan Berkas Rekam Medis Rawat Jalan Di Rumah Sakit Umum Madani Medan. Jurnal Ilmiah Perekam Dan Informasi Kesehatan Imelda (JIPIKI), 3(1), 417-424.

Setyawan, F. E. B., \& Supriyanto, S. (2020). Manajemen rumah sakit. Zifatama Jawara.

Stiyawan, H., Mansur, M., \& Noor, V. M. M. (2018). Dampak Tidak Patuh Terhadap Pelaksanaan SOP Alur Rawat Jalan di Rumah Sakit" X" Malang. Ekspektra: Jurnal Bisnis Dan Manajemen, 2(1), 1-16.

Wati, N. W. K. W., Riyanto, S., \& Hendrawan, R. Y. E. (2020). Pengaruh Penerapan Indikator Mutu Layanan Klinis Bagian Rekam Medis terhadap Kepuasan Pasien di Puskesmas Gambut. Jurnal Kesehatan Indonesia, 11(1), 35-40.

Wijayanti, R., \& Nuraini, N. (2017). Analisis Faktor Petugas dalam Pengisian Kartu Ibu dan Alur Rujukan Ibu Hamil Risti. Prosiding. 
Wulandari, R. D., Ridlo, I. A., Supriyanto, S., Qomarrudin, M. B., Damayanti, N. A., \& Laksono, A. D. (2019). Pengaruh Pelaksanaan Akreditasi Puskesmas terhadap Kepuasan Pasien (The Influence of Primary Health Care Accreditation on Patient Satisfaction). Media Kesehat Masy Indones, 15(3), 228-236.

(C) 2021 by the authors. Submitted for possible open access publication under the terms : (c) (i) (2) conditions of the Creative Commons Attribution (CC BY SA) lice 